\title{
Early outcomes and safety of the minimally invasive, lateral retroperitoneal transpsoas approach for adult degenerative scoliosis
}

\author{
Elias Dakwar, M.D., Rafael F. Cardona, M.D., Donald A. Smith, M.D., \\ and Juan S. URIbe, M.D. \\ Department of Neurological Surgery, University of South Florida, Tampa, Florida
}

\begin{abstract}
Object. The object of this study was to evaluate an alternative surgical approach to degenerative thoracolumbar deformity in adults. The authors present their early experience with the minimally invasive, lateral retroperitoneal transpsoas approach for placing interbody grafts and providing anterior column support for adult degenerative deformity.

Methods. The authors retrospectively reviewed a prospectively acquired database of all patients with adult thoracolumbar degenerative deformity treated with the minimally invasive, lateral retroperitoneal transpsoas approach at our institution. All patient data were recorded including demographics, preoperative evaluation, procedure used, postoperative follow-up, operative time, blood loss, length of hospital stay, and complications. The Oswestry Disability Index and visual analog scale (for pain) were also administered pre- and postoperatively as early outcome measures. All patients were scheduled for follow-up postoperatively at weeks 2, 6, 12, and 24, and at 1 year.

Results. The authors identified 25 patients with adult degenerative deformity who were treated using the minimally invasive, lateral retroperitoneal transpsoas approach. All patients underwent discectomy and lateral interbody graft placement for anterior column support and interbody fusion. The mean total blood loss was $53 \mathrm{ml}$ per level. The average length of stay in the hospital was 6.2 days. Mean follow-up was 11 months (range 3-20 months). A mean improvement of 5.7 points on visual analog scale scores and $23.7 \%$ on the Oswestry Disability Index was observed. Perioperative complications include 1 patient with rhabdomyolysis requiring temporary hemodialysis, 1 patient with subsidence, and 1 patient with hardware failure. Three patients $(12 \%)$ experienced transient postoperative anterior thigh numbness, ipsilateral to the side of approach. In this series, 20 patients $(80 \%)$ were identified who had more than 6 months of follow-up and radiographic evidence of fusion. The minimally invasive, lateral retroperitoneal transpsoas approach, without the use of osteotomies, did not correct the sagittal balance in approximately one-third of the patients.

Conclusions. Degenerative scoliosis of the adult spine is secondary to asymmetrical degeneration of the discs. Surgical decompression and correction of the deformity can be performed from an anterior, posterior, or combined approach. These procedures are often associated with long operative times and a high incidence of complications. The authors' experience with the minimally invasive, lateral retroperitoneal transpsoas approach for placement of a large interbody graft for anterior column support, restoration of disc height, arthrodesis, and realignment is a feasible alternative to these procedures. (DOI: 10.3171/2010.1.FOCUSO9282)
\end{abstract}

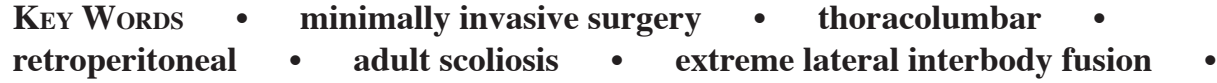 direct lateral interbody fusion}

$\mathrm{D}$ E novo or degenerative scoliosis in the adult spine is a $3 \mathrm{D}$ deformity that affects the spine in the coronal, sagittal, and axial planes. Degenerative scoliosis is believed to develop because of asymmetrical degeneration of discs, osteoporosis, and vertebral body compression fractures..$^{15}$ The primary presenting symptom of this condition is chronic back pain in the major-

\footnotetext{
Abbreviations used in this paper: $\mathrm{BMP}=$ bone morphogenetic protein; $\mathrm{EMG}=$ electromyography; ODI = Oswestry Disability Index; VAS = visual analog scale.
}

ity of patients. Patients can also present with neurogenic claudication caused by the concurrent stenosis with a structural degenerative deformity. ${ }^{20,37}$

The goals of adult deformity surgery are to obtain sagittal and coronal balance, pain relief, and solid fusion. ${ }^{4,14}$ In many cases, these patients require treatment strategies that address both the anterior and posterior columns. An interbody graft placement allows for restoration of anterior column height, arthrodesis, and correction of the deformity. Anterior column support, by way of interbody graft placement, can be achieved using an 


\section{E. Dakwar et al.}

TABLE 1: Clinical summary of 25 patients with adult degenerative deformity treated using the minimally invasive, lateral retroperitoneal transpsoas approach*

\begin{tabular}{|c|c|c|c|c|c|c|c|c|c|c|}
\hline \multirow[b]{2}{*}{$\begin{array}{l}\text { Case } \\
\text { No. }\end{array}$} & \multirow[b]{2}{*}{$\begin{array}{l}\text { Age (yrs), } \\
\text { Sex }\end{array}$} & \multirow[b]{2}{*}{ Interbody Levels } & \multirow[b]{2}{*}{$\begin{array}{c}\text { Instru- } \\
\text { mentation }\end{array}$} & \multirow[b]{2}{*}{$\begin{array}{c}\text { Fixation } \\
\text { Levels }\end{array}$} & \multirow[b]{2}{*}{ Fusion } & \multirow[b]{2}{*}{$\begin{array}{l}\text { Follow- } \\
\text { Up (mos) }\end{array}$} & \multicolumn{2}{|c|}{ Coronal Angle $\left(^{\circ}\right)$} & \multirow[b]{2}{*}{$\begin{array}{l}\text { Sagittal } \\
\text { Balance }\end{array}$} & \multirow[b]{2}{*}{ Complications } \\
\hline & & & & & & & Preop & Postop & & \\
\hline 1 & $74, F$ & L2-3, L3-4 & LP & L2-4 & yes & 20 & 13 & 8 & no & \\
\hline 2 & $68, M$ & L3-4, L4-5 & LP & L3-5 & yes & 20 & 10 & 5 & yes & subsidence \\
\hline 3 & $65, F$ & L1-2, L2-3, L3-4, L4-5 & PS & T10-llia & yes & 20 & 25 & 4 & no & \\
\hline 4 & $64, M$ & L2-3, L3-4, L4-5 & LP & L2-5 & yes & 20 & 11 & 4 & yes & \\
\hline 5 & $77, \mathrm{~F}$ & L2-3, L3-4, L4-5 & LP & L2-5 & yes & 18 & 16 & 7 & yes & \\
\hline 6 & $51, F$ & L3-4, L4-5 & LP & L3-5 & yes & 17 & 22 & 2 & yes & \\
\hline 7 & $50, M$ & L3-4, L4-5 & none & L3-5 & yes & 17 & 17 & 7 & yes & \\
\hline 8 & $72, F$ & L2-3, L3-4, L4-5 & LP & L2-5 & yes & 13 & NA & 12 & yes & numbness \\
\hline 9 & $50, M$ & L1-2, L2-3, L3-4, L4-5 & LP & $\mathrm{L} 1-5$ & yes & 13 & 23 & 19 & no & hardware failure \\
\hline 10 & $65, M$ & L1-2, L2-3, L3-4, L4-5 & LP & $\mathrm{L} 1-5$ & yes & 13 & 22 & 1 & yes & \\
\hline 11 & $65, F$ & L2-3, L3-4, L4-5 & LP \& PS & L2-S1 & yes & 11 & 20 & 7 & yes & \\
\hline 12 & $65, M$ & L2-3, L3-4, L4-5 & LP & L2-5 & yes & 10 & 18 & 2 & yes & \\
\hline 13 & $70, M$ & L3-4, L4-5 & LP & L3-5 & yes & 10 & 13 & 4 & yes & \\
\hline 14 & $64, \mathrm{M}$ & L3-4, L4-5 & LP & L3-5 & yes & 10 & 21 & 10 & yes & \\
\hline 15 & $55, \mathrm{~F}$ & L3-4, L4-5 & LP & L3-5 & yes & 10 & 24 & 2 & yes & \\
\hline 16 & $56, F$ & L2-3, L3-4, L4-5 & LP & L2-5 & yes & 9 & 12 & 4 & yes & \\
\hline 17 & $53, F$ & L4-5 & LP & L4-5 & yes & 9 & 11 & 3 & no & \\
\hline 18 & $70, F$ & T12-L1, L1-2, L2-3, L3-4, L4-5 & PS & T10-llia & yes & 9 & 48 & 8 & no & numbness \\
\hline 19 & $35, F$ & T12-L1, L1-2, L2-3, L3-4, L4-5 & PS & T10-llia & yes & 8 & 49 & 12 & yes & \\
\hline 20 & $75, \mathrm{M}$ & L2-3, L3-4, L4-5 & PS & T12-S1 & yes & 7 & 19 & 2 & no & \\
\hline 21 & $60, M$ & $\begin{array}{l}\text { T10-11, T11-12, T12-L1, L1-2, } \\
\text { L2-3, L3-4 }\end{array}$ & none & T10-L4 & no & 5 & 34 & 24 & NA & rhabdomyolysis \\
\hline 22 & $72, F$ & L2-3, L3-4, L4-5 & PS & L2-5 & no & 4 & 18 & 3 & no & \\
\hline 23 & $52, F$ & L3-4, L4-5 & LP & L3-5 & no & 4 & 15 & 1 & yes & \\
\hline 24 & $75, \mathrm{~F}$ & L2-3, L3-4, L4-5 & PS & L2-5 & no & 4 & 10 & 3 & yes & numbness \\
\hline 25 & $59, F$ & L1-2, L2-3, L3-4, L4-5 & PS & T11-Ilia & no & 3 & 36 & 6 & no & \\
\hline
\end{tabular}

* $\mathrm{LP}=$ lateral plate; $\mathrm{NA}=$ not available; $\mathrm{PS}=$ pedicle screws.

anterior, posterior, or lateral approach. The minimally invasive, lateral retroperitoneal transpsoas approach allows for interbody graft placement and anterior column support, while avoiding the potential complications associated with anterior or posterior approaches. ${ }^{26}$ In this paper, we describe our early experience with the minimally invasive, lateral retroperitoneal transpsoas approach for discectomy and interbody graft delivery for adult degenerative scoliosis.

\section{Methods}

We retrospectively reviewed a prospectively acquired database of all patients with adult thoracolumbar degenerative deformity treated via the minimally invasive, lateral retroperitoneal transpsoas approach at our institution. All patient data were recorded, including demographics, preoperative evaluation, procedure used, postoperative follow-up, operative time, blood loss, length of hospital stay, and complications. We also administered the ODI and the VAS (for pain) pre- and postoperatively as early outcome measures. All patients were scheduled for follow-up postoperatively at weeks $2,6,12$, and 24 , and at 1 year.

All patients presented with mechanical back pain and/or radicular pain that was refractory to at least 12 months of conservative management. Patients with idiopathic curves or scoliosis secondary to neurological or neuromuscular conditions were excluded from the study. The surgical procedure, as previously described, ${ }^{26}$ consisted of placing patients in the lateral decubitus position, performing fluoroscopic localization of the affected level, and using lateral retroperitoneal blunt dissection to expose the lateral surface of the spine. Once an armmounted expandable retractor was placed, discectomies and placement of interbody grafts were performed laterally. The discectomies were performed across the midline to the contralateral annulus, while preserving the anterior and posterior longitudinal ligaments. The interbody grafts were made from polyetheretherketone and filled with recombinant human BMP-2, tricalcium phosphate, and hydroxyapatite. The amount of BMP that was used was approximately $0.7 \mathrm{~cm}^{3}$ of recombinant human 

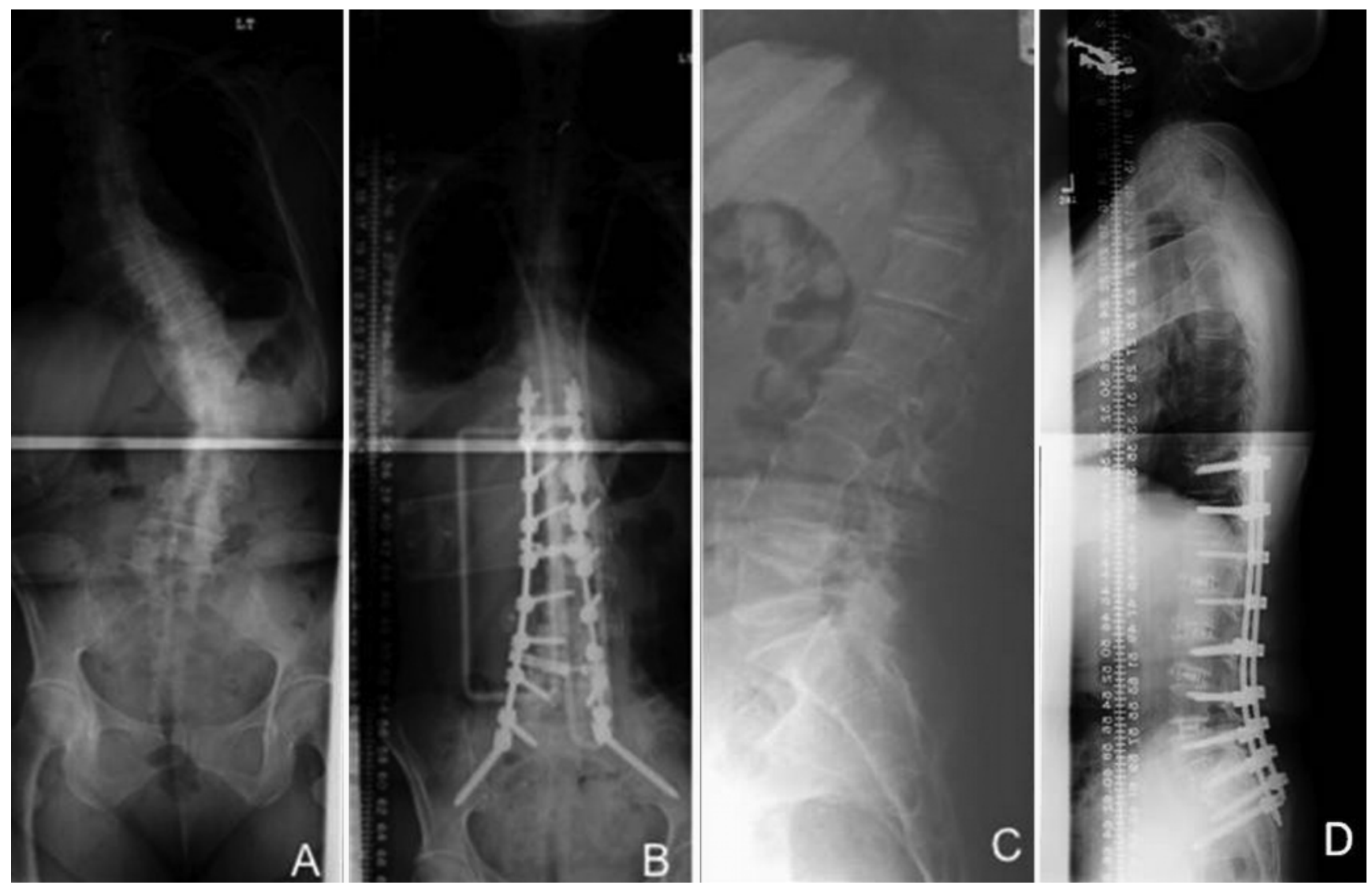

FIG. 1. Standing radiographs obtained in a patient who underwent a 5-level lateral transpsoas lumbar interbody fusion, and posterior instrumentation from T-10 to the ilia. Views shown are anteroposterior preoperative (A) and postoperative (B), and lateral preoperative (C) and postoperative (D).

BMP-2/absorbable collagen sponge per interbody level. The interbody cages were positioned on the apophyseal ring and measured $18 \mathrm{~mm}$ wide, $8-12 \mathrm{~mm}$ in height, and 55-60 $\mathrm{mm}$ in length. Interbody grafts were augmented with lateral plates or posterior pedicle screws for stability and completion of the deformity correction. Additionally, EMG neuromonitoring was used throughout the procedure to aid in localizing the motor nerves and roots of the lumbar plexus and potentially prevent injury.

\section{Results}

Between 2007 and 2009, 25 patients (15 women, 10 men) underwent a minimally invasive, lateral retroperitoneal transpsoas approach for the placement of interbody grafts in the treatment of adult degenerative deformity (Table 1). The mean patient age was 62.5 years (range 35-77 years). All patients successfully underwent lateral discectomies and placement of interbody grafts for anterior column support and interbody fusion (Figs. 1 and 2). Seventy-six lateral interbody grafts were placed. Twenty-three patients underwent additional instrumentation, 7 with pedicle screws, 15 with lateral plates, and 1 with both. The mean operative time from induction to extubation was 108 minutes per level. A significant portion of this time was devoted to patient positioning and fluoroscopic localization of the targeted levels. The mean total blood loss was $53 \mathrm{ml}$ per level. The average length of stay in the hospital was 6.2 days. Mean follow-up was 11 months (range 3-20 months). No patient required a blood transfusion. There were no intraoperative CSF leaks, wound infections, or postoperative weaknesses identified. There were no injuries to the peritoneal or retroperitoneal structures. There were no deep venous thromboses, urinary tract infections, or ileus identified. Perioperative complications include 1 patient with rhabdomyolysis requiring temporary hemodialysis, 1 patient with asymptomatic subsidence, and 1 patient with asymptomatic hardware failure. Three patients (12\%) experienced transient postoperative anterior thigh numbness ipsilateral to the side of approach in the distribution of the anterior femoral cutaneous nerve. Evidence of fusion was assessed radiographically in all patients with more than 6 months of follow-up. In our series, we identified 20 patients $(80 \%)$ who underwent more than 6 months of follow-up; all of these patients demonstrated radiographic evidence of fusion on $\mathrm{CT}$ scans or flexion-extension radiographs.

Outcome measures assessed include the VAS pain score and the ODI (Fig. 3). Mean improvement of 5.7 points in VAS scores and $23.7 \%$ in the ODI was observed. The VAS score averaged 8.1 preoperatively and improved to 2.4 at the last follow-up visit. The ODI averaged $53.6 \%$ preoperatively and improved to $29.9 \%$ at the last followup visit. 


\section{E. Dakwar et al.}

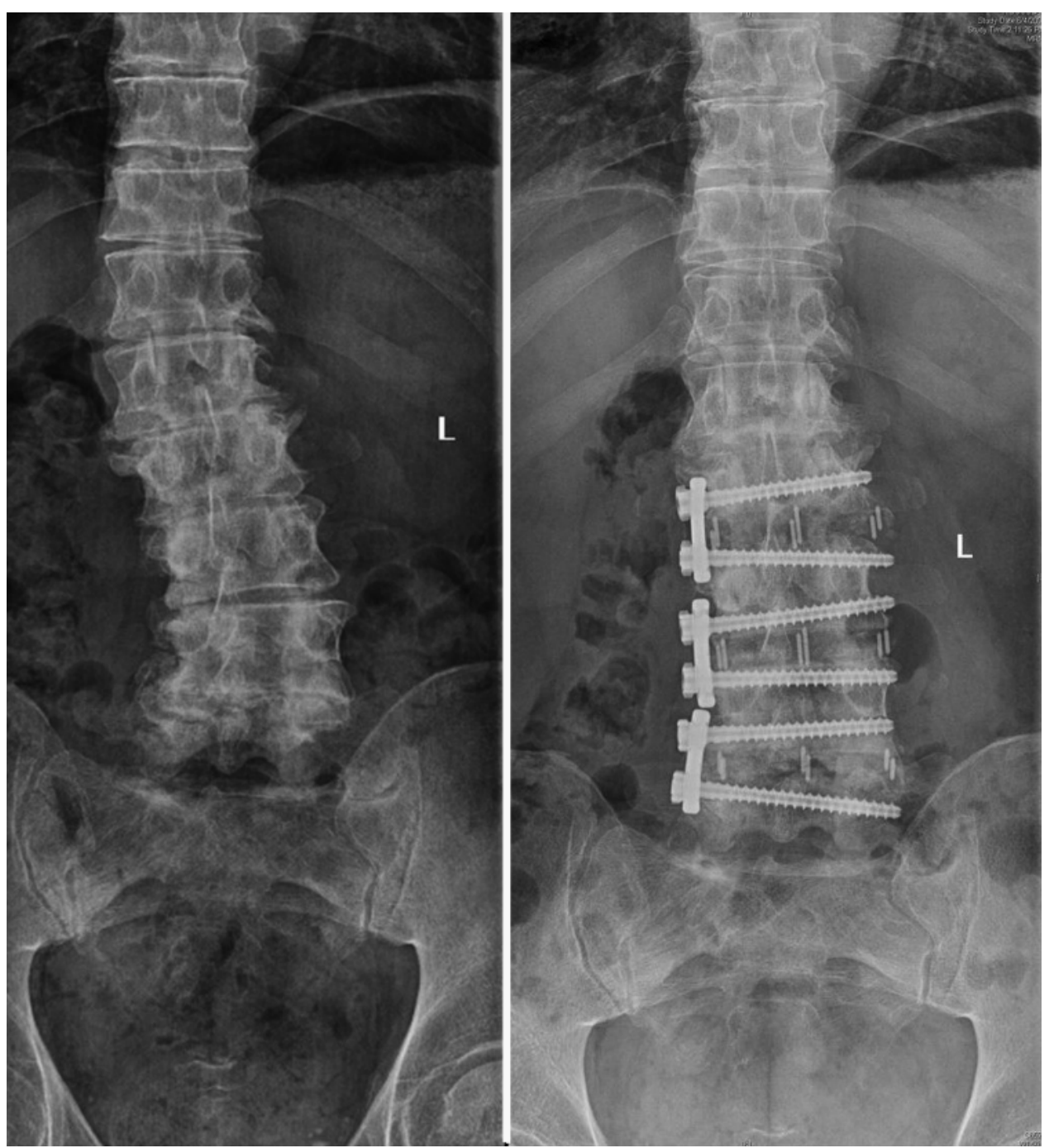

FIG. 2. Preoperative (left) and postoperative (right) standing radiographs obtained in a patient who underwent a 3-level lateral transpsoas lumbar interbody fusion with lateral plate fixation.

\section{Discussion}

Adult degenerative or de novo scoliosis is believed to develop as a result of asymmetrical degeneration of the spine. It most often occurs in the lumbar spine and typically presents with pain as the primary complaint in $90 \%$ of patients..$^{20,37}$ The pain may be axial, radicular, or both. ${ }^{33}$ Axial pain is more prevalent among older patients with spinal deformity, as compared with younger patients. ${ }^{19}$ This pain occurs most commonly from a combination of muscle fatigue, trunk imbalance, facet arthropathy, and degenerative disc disease. ${ }^{5}$ All patients should first undergo conservative treatment prior to being considered for surgical intervention. ${ }^{4}$ However, surgically treated patients with adult scoliosis had a significantly greater improvement in back pain and quality of life when compared with nonoperatively treated patients. ${ }^{7,34}$ Once a patient has failed to respond to conservative treatment or has met the indications for surgery, ${ }^{14}$ the surgeon is faced with the decision to approach the spine from the anterior or posterior aspect, or a combination of both.
The goals of adult deformity surgery are to obtain sagittal and coronal balance, pain relief, and solid fusion. Typically, wires, hooks, and pedicle screws have been used to address the posterior columns in deformity correction operations.${ }^{14}$ In many cases, patients require treatment strategies that address both the anterior and posterior columns. Unlike adolescent spinal curves, adult deformities are usually rigid and require a combined anterior-posterior approach. ${ }^{5}$ This approach usually involves multiple anterior releases, followed by a posterior procedure in which the deformity correction is completed. ${ }^{14}$ Anterior releases can range from a discectomy to a corpectomy, which aid in extending the spine. Anterior reconstruction with a bone graft or cage maintains distraction between the endplates, provides an area for arthrodesis, corrects kyphosis, and restores lordosis. ${ }^{35}$

Structural anterior column support provides several benefits such as improved stability, decreased stress on posterior instrumentation, improved fusion rates, and better lumbar lordosis. $13,16,25,27,28,38$ Anterior column support, by way of interbody graft placement, can be achieved 


\section{Lateral transpsoas approach for adult degenerative scoliosis}
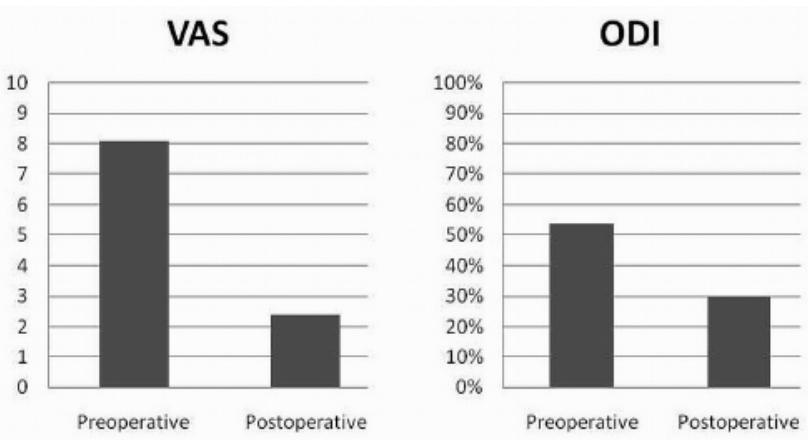

FIG. 3. Bar graphs showing mean preoperative and postoperative values of the VAS (for pain) and ODI.

with an anterior, posterior, or lateral approach. Anterior interbody fusion allows complete visualization of the disc space and placement of a large interbody graft. Reported complications from the anterior approach include retrograde ejaculation, great vessel injury, ureteral trauma, and prolonged ileus. ${ }^{6,12,24,30,31}$ The posterior and transforaminal interbody fusions allow incomplete anterior release and smaller cage sizes when compared with the anterior approach. The posterior placement of interbody grafts places the nerve roots at risk for traction injuries.

The minimally invasive, lateral retroperitoneal transpsoas approach provides the surgeon with an alternative option when placing an interbody graft. The goals of minimally invasive surgery are to minimize dissection and trauma of muscle related to the approach, reduce blood loss, shorten hospital stays, mobilize patients early, and hasten recovery. ${ }^{2,11,36}$ Similar to the anterior approach, the minimally invasive lateral approach allows for placement of a large interbody graft without need for an access surgeon. When compared with posteriorly placed interbody grafts, laterally placed grafts have a much larger area for potential fusion and are able to restore disc height and lordosis more easily.

When planning to surgically correct adult deformity secondary to degenerative changes of the spine, we must consider the patient population undergoing the operation. Degenerative scoliosis is generally observed in the older population, who tend to suffer from osteoporosis and a higher number of medical comorbidities. ${ }^{1}$ Advanced age and medical comorbidities have been reported to cause more complications in deformity surgery. ${ }^{8,29}$ In addition, the surgical correction of adult deformity is believed to be more difficult than in adolescent patients and is associated with a higher rate of complications. ${ }^{5,10,32,33}$ The pseudarthrosis rate after deformity surgery for adult patients after long fusions has been reported to be $24 \%$, which is significantly higher than in pediatric patients. ${ }^{17}$ Despite the increased risk, adult patients with scoliosis who were older than 65 years of age and were treated operatively experienced significantly less pain, a better quality of life, and were more satisfied than patients treated conservatively. ${ }^{21}$

Scoliosis is a 3D deformity of the spine and all 3 planes need to be addressed to maximize patient outcomes. These procedures tend to be lengthy and invasive due to the need to expose and fuse a large portion of the spine. The incidence of complications has been reported to be between 20 and $80 \% .^{1,8,22,39}$ In his series of patients undergoing posterior fusion and instrumentation for degenerative lumbar scoliosis, Cho et al. ${ }^{9}$ reported an overall complication rate of $68 \%$ and an early perioperative complication rate of $30 \%$. One of the main risk factors that increased the early perioperative complications in this study was a blood loss of more than 2 liters. ${ }^{9}$

Although the minimally invasive, lateral retroperitoneal transpsoas approach avoids many of the disadvantages of both the anterior and posterior approaches, it does have certain limitations and disadvantages of its own. Secondary to the anatomical constraints of the iliac crest, the L5-S1 disc space is not easily or safely approachable with this technique. This approach relies on indirect decompression of the spinal canal and neural foramen by restoring disc height and lordosis. If supplemental posterior instrumentation or direct decompression is required, a separate posterior incision and approach must be performed.

As with all new techniques and technologies associated with minimally invasive spine surgery, there is a steep learning curve associated with this approach. The use of EMG neural monitoring and intraoperative fluoroscopy is critical to the safe passage within the psoas muscle. Prior reports of lateral retroperitoneal approaches included mobilization of the psoas muscle from the lumbar spine, with a high incidence (30\%) of paresthesias in the thigh/groin region..$^{3,23}$ Knight et al. ${ }^{18}$ reported a $10 \%$ incidence of lateral femoral cutaneous nerve deficit and a $3 \%$ incidence of L-4 motor deficit using the lateral retroperitoneal transpsoas approach. In our series of patients, we identified 3 patients (12\%) with transient postoperative ipsilateral sensory deficits that resolved by the 3-month follow-up visit. There were no patients with postoperative motor deficits.

As stated above, in our series of patients, the incidence of postoperative sensory deficit (12\%) using the minimally invasive, lateral retroperitoneal transpsoas approach is consistent with rates in the published literature. ${ }^{18}$ The approach-related complications of sensory deficits are not prevented by EMG neuromonitoring, which only helps identify motor nerves. Because most of these deficits are transient, we believe they are stretch or neurapraxic injuries. The origin is most likely secondary to placement of the dilators/retractor system and aggressive dissection of the retroperitoneal space. In an effort to minimize these approach-related complications, we decrease the amount of lateral flexion of the patient and flex the hip during positioning. We believe that this may decrease the amount of tension on the lumbar plexus. Some nerves have mixed motor and sensory fibers, such as the femoral nerve, which carries the fibers of the anterior femoral cutaneous nerve. Neuromonitoring using EMG will not directly assist in detection or localization of sensory nerves; however, locating the femoral nerve will indirectly indicate the location of the sensory fibers of the anterior femoral cutaneous nerve. In addition, we advocate acquiring knowledge of the anatomy of the disc space in relation to the neural structures, gentle dissection, and minimizing expansion of the retractor whenever possible. 


\section{E. Dakwar et al.}

In addition to the transient sensory deficits already noted, 1 patient suffered from perioperative rhabdomyolysis. He underwent a 6-level interbody cage placement via the lateral transpsoas approach. This patient required approximately 4 months of hemodialysis prior to return of his renal function. Secondary to the rhabdomyolysis, he did not undergo the second stage of his surgery for placement of posterior pedicle screws.

\section{Conclusions}

Degenerative scoliosis of the adult spine is secondary to asymmetrical degeneration of the discs. Surgical decompression and correction of the deformity can be performed from an anterior, posterior, or combined approach. These procedures are often associated with long operative times and a high incidence of complications. Our experience using the minimally invasive, lateral retroperitoneal transpsoas approach for placement of a large interbody graft for anterior column support, restoration of disc height, arthrodesis, and realignment shows that this approach is a feasible alternative to more traditional approaches.

\section{Disclosure}

Dr. Uribe has served as a consultant to Nuvasive, and has received clinical or research support for this study from Nuvasive.

Author contributions to the study and manuscript preparation include the following. Acquisition of data: RF Cardona. Drafting the article: E. Dakwar. Study supervision: DA Smith, JS Uribe.

\section{References}

1. Aebi M: The adult scoliosis. Eur Spine J 14:925-948, 2005

2. Benglis DM, Elhammady MS, Levi AD, Vanni S: Minimally invasive anterolateral approaches for the treatment of back pain and adult degenerative deformity. Neurosurgery 63 (3 Suppl):191-196, 2008

3. Bergey DL, Villavicencio AT, Goldstein T, Regan JJ: Endoscopic lateral transpsoas approach to the lumbar spine. Spine (Phila Pa 1976) 29:1681-1688, 2004

4. Birknes JK, White AP, Albert TJ, Shaffrey CI, Harrop JS: Adult degenerative scoliosis: a review. Neurosurgery 63 (3 Suppl):94-103, 2008

5. Bradford DS, Tay BK, Hu SS: Adult scoliosis: surgical indications, operative management, complications, and outcomes Spine (Phila Pa 1976) 24:2617-2629, 1999

6. Brau SA, Delamarter RB, Kropf MA, Watkins RG III, Williams LA, Schiffman ML, et al: Access strategies for revision in anterior lumbar surgery. Spine (Phila Pa 1976) 33:16621667,2008

7. Bridwell KH, Glassman S, Horton W, Shaffrey C, Schwab F, Zebala LP, et al: Does treatment (nonoperative and operative) improve the two-year quality of life in patients with adult symptomatic lumbar scoliosis: a prospective multicenter evidence-based medicine study. Spine (Phila Pa 1976) 34:21712178, 2009

8. Carreon LY, Puno RM, Dimar JR II, Glassman SD, Johnson JR: Perioperative complications of posterior lumbar decompression and arthrodesis in older adults. J Bone Joint Surg Am 85-A:2089-2092, 2003

9. Cho KJ, Suk SI, Park SR, Kim JH, Kim SS, Choi WK, et al: Complications in posterior fusion and instrumentation for degenerative lumbar scoliosis. Spine (Phila Pa 1976) 32:22322237, 2007
10. Deviren V, Berven S, Kleinstueck F, Antinnes J, Smith JA, Hu SS: Predictors of flexibility and pain patterns in thoracolumbar and lumbar idiopathic scoliosis. Spine (Phila Pa 1976) 27:2346-2349, 2002

11. Eck JC, Hodges S, Humphreys SC: Minimally invasive lumbar spinal fusion. J Am Acad Orthop Surg 15:321-329, 2007

12. Gumbs AA, Hanan S, Yue JJ, Shah RV, Sumpio B: Revision open anterior approaches for spine procedures. Spine J 7:280-285, 2007

13. Hackenberg L, Halm H, Bullmann V, Vieth V, Schneider M, Liljenqvist U: Transforaminal lumbar interbody fusion: a safe technique with satisfactory three to five year results. Eur Spine J 14:551-558, 2005

14. Heary RF, Kumar S, Bono CM: Decision making in adult deformity. Neurosurgery 63 (3 Suppl):69-77, 2008

15. Herkowitz HN, Kurz LT: Degenerative lumbar spondylolisthesis with spinal stenosis. A prospective study comparing decompression with decompression and intertransverse process arthrodesis. J Bone Joint Surg Am 73:802-808, 1991

16. Hsieh PC, Koski TR, O’Shaughnessy BA, Sugrue P, Salehi S, Ondra S, et al: Anterior lumbar interbody fusion in comparison with transforaminal lumbar interbody fusion: implications for the restoration of foraminal height, local disc angle, lumbar lordosis, and sagittal balance. J Neurosurg Spine 7:379-386, 2007

17. Kim YJ, Bridwell KH, Lenke LG, Rhim S, Cheh G: Pseudarthrosis in long adult spinal deformity instrumentation and fusion to the sacrum: prevalence and risk factor analysis of 144 cases. Spine (Phila Pa 1976) 31:2329-2336, 2006

18. Knight RQ, Schwaegler P, Hanscom D, Roh J: Direct lateral lumbar interbody fusion for degenerative conditions: early complication profile. J Spinal Disord Tech 22:34-37, 2009

19. Kostuik JP, Bentivoglio J: The incidence of low-back pain in adult scoliosis. Spine (Phila Pa 1976) 6:268-273, 1981

20. Kostuik JP, Israel J, Hall JE: Scoliosis surgery in adults. Clin Orthop Relat Res 93:225-234, 1973

21. Li G, Passias P, Kozanek M, Fu E, Wang S, Xia Q, et al: Adult scoliosis in patients over sixty-five years of age: outcomes of operative versus nonoperative treatment at a minimum twoyear follow-up. Spine (Phila Pa 1976) 34:2165-2170, 2009

22. Marchesi DG, Aebi M: Pedicle fixation devices in the treatment of adult lumbar scoliosis. Spine (Phila Pa 1976) 17 (8 Suppl):S304-S309, 1992

23. Nakamura H, Ishikawa T, Konishi S, Seki M, Yamano Y: Psoas strapping technique: a new technique for laparoscopic anterior lumbar interbody fusion. J Am Coll Surg 191:686688,2000

24. Nguyen HV, Akbarnia BA, van Dam BE, Raiszadeh K, Bagheri R, Canale S, et al: Anterior exposure of the spine for removal of lumbar interbody devices and implants. Spine (Phila Pa 1976) 31:2449-2453, 2006

25. Niemeyer TK, Koriller M, Claes L, Kettler A, Werner K, Wilke HJ: In vitro study of biomechanical behavior of anterior and transforaminal lumbar interbody instrumentation techniques. Neurosurgery 59:1271-1277, 2006

26. Ozgur BM, Aryan HE, Pimenta L, Taylor WR: Extreme Lateral Interbody Fusion (XLIF): a novel surgical technique for anterior lumbar interbody fusion. Spine J 6:435-443, 2006

27. Ploumis A, Wu C, Fischer G, Mehbod AA, Wu W, Faundez A, et al: Biomechanical comparison of anterior lumbar interbody fusion and transforaminal lumbar interbody fusion. J Spinal Disord Tech 21:120-125, 2008

28. Potter BK, Freedman BA, Verwiebe EG, Hall JM, Polly DW Jr, Kuklo TR: Transforaminal lumbar interbody fusion: clinical and radiographic results and complications in 100 consecutive patients. J Spinal Disord Tech 18:337-346, 2005

29. Raffo CS, Lauerman WC: Predicting morbidity and mortality of lumbar spine arthrodesis in patients in their ninth decade. Spine (Phila Pa 1976) 31:99-103, 2006 


\section{Lateral transpsoas approach for adult degenerative scoliosis}

30. Santos ER, Pinto MR, Lonstein JE, Denis F, Garvey TA, Perra JH, et al: Revision lumbar arthrodesis for the treatment of lumbar cage pseudoarthrosis: complications. J Spinal Disord Tech 21:418-421, 2008

31. Schwender JD, Casnellie MT, Perra JH, Transfeldt EE, Pinto MR, Denis F, et al: Perioperative complications in revision anterior lumbar spine surgery: incidence and risk factors. Spine (Phila Pa 1976) 34:87-90, 2009

32. Shapiro GS, Taira G, Boachie-Adjei O: Results of surgical treatment of adult idiopathic scoliosis with low back pain and spinal stenosis: a study of long-term clinical radiographic outcomes. Spine (Phila Pa 1976) 28:358-363, 2003

33. Slosar PJ: Indications and outcomes of reconstructive surgery in chronic pain of spinal origin. Spine (Phila Pa 1976) 27:2555-2563, 2002

34. Smith JS, Shaffrey CI, Berven S, Glassman S, Hamill C, Horton $\mathrm{W}$, et al: Improvement of back pain with operative and nonoperative treatment in adults with scoliosis. Neurosurgery 65:86-94, 2009

35. Sweet FA, Lenke LG, Bridwell KH, Blanke KM, Whorton J: Prospective radiographic and clinical outcomes and complications of single solid rod instrumented anterior spinal fu- sion in adolescent idiopathic scoliosis. Spine (Phila Pa 1976) 26:1956-1965, 2001

36. Wang MY, Anderson DG, Poelstra KA, Ludwig SC: Minimally invasive posterior fixation. Neurosurgery 63 (3 Suppl): 197-203, 2008

37. Winter RB, Lonstein JE, Denis F: Pain patterns in adult scoliosis. Orthop Clin North Am 19:339-345, 1988

38. Wu CH, Wong CB, Chen LH, Niu CC, Tsai TT, Chen WJ: Instrumented posterior lumbar interbody fusion for patients with degenerative lumbar scoliosis. J Spinal Disord Tech 21:310-315, 2008

39. Zurbriggen C, Markwalder TM, Wyss S: Long-term results in patients treated with posterior instrumentation and fusion for degenerative scoliosis of the lumbar spine. Acta Neurochir (Wien) 141:21-26, 1999

Manuscript submitted November 15, 2009.

Accepted January 13, 2010.

Address correspondence to: Elias Dakwar, M.D., 2 Tampa General Circle, 7th floor, Tampa, Florida 33606. email: edakwar@ health.usf.edu. 